\title{
A IDADE DO SERROTE: ENCAMINHAMENTO DE UMA LEITURA
}

Jayme Loureiro $^{1}$

\section{RESUMO}

$\mathrm{O}$ artigo tem por objetivo propor uma leitura interpretativa de $A$ idade do serrote, autobiografia que abarca as memórias da infância e da adolescência de Murilo Mendes, que se fundamente na articulação entre o processo de poetização do texto (tanto no nível formal quanto do conteúdo) e o projeto poético do autor.

PALAVRAS-CHAVE: Murilo Mendes; $A$ idade do serrote; autobiografia; projeto poético.

\section{ABSTRACT}

The article proposes an interpretative reading of $A$ idade do serrote, an autobiography comprehending Murilo Mendes's childhood and youth recollections, a reading grounded on the articulation between the text's poeticization (both in formal as in content level) and the author's poetic project.

KEYWORDS: Murilo Mendes; $A$ idade do serrote; autobiography; poetic project.

Laís Corrêa de Araújo abre do seguinte modo a "Nota biográfica” de seu clássico estudo sobre Murilo Mendes:

Murilo (Monteiro) Mendes nasceu em Juiz de Fora, Minas Gerais, a 13 de maio de 1901. Seus pais se chamavam Onofre Mendes ("servidor público. Do próximo. Escrivão do registro de títulos e hipotecas") e Elisa Valentina Monteiro de Barros Mendes ("afeiçoada ao canto e ao piano, morre de parto com vinte e oito anos"). Murilo, o segundo filho do casal, tinha apenas um ano e meio quando perdeu a mãe. O pai casou-se novamente, com Maria José Monteiro Mendes ("minha segunda mãe, Maria José, grande dama da cozinha e salão, resume a ternura brasileira. Risquei do vocabulário a palavra madrasta”), acrescentando aos dois primeiros filhos mais cinco irmãos. (ARAÚJO, 2000, p. 11).

Talvez não seja muito elegante iniciar o artigo com uma longa citação; pode mesmo passar a impressão de que a aproveito para trazer ao leitor alguns dados básicos da vida de Murilo Mendes, escapando assim de compor uma sintética biografia, item que talvez devesse constar num texto que tem por objeto $A$ idade do serrote, autobiografia que abarca as memórias da infância e da adolescência do poeta $^{2}$. Não nego tal intenção - e eis aí algumas informações importantes sobre a data, o local de nascimento e os pais de Murilo - na medida em que descarto a apresentação de mais uma notícia biográfica, que com certeza seria mero apanhado ou repetição do que já se encontra bem esmiuçado em outras obras.

A citação, fixada logo na entrada, visa essencialmente a outro objetivo: mostrar que fragmentos extraídos de $A$ idade do serrote, citados entre parênteses e entre aspas, são empregados como fonte documental para dar sustentação aos dados biográficos expostos. Tal emprego parece, à primeira vista, plenamente justificável e nem um pouco problemático; porém Laís Corrêa de Araújo (2000, p. 127), ao examinar as obras publicadas por Murilo Mendes na década de 1960, vai fazer a seguinte observação a respeito de $A$ idade do serrote: "(memória? invenção?)". Mais que apontar uma suposta

\footnotetext{
${ }^{1}$ Doutor em Literatura Brasileira pela Universidade de São Paulo. Este artigo é uma versão de um capítulo da tese de doutorado $A$ formação de um enfant terrible: poetização e resistência em $A$ idade do serrote, defendida em 25/02/2010. Email: jyl@uol.com.br

${ }^{2}$ O livro foi escrito em Roma entre 1965 e 1966 e publicado pela editora Sabiá em 1968.
} 
contradição na leitura que a autora faz do livro, tratando-o inicialmente como documento para mais adiante colocar em suspeição seu caráter testemunhal, o importante é assinalar que tal leitura reflete não só a própria ambiguidade do gênero autobiográfico (gênero de fronteira que flutua entre o relato objetivo e fidedigno dos fatos passados e a construção subjetiva e artificial desse mesmo passado) como põe em destaque a dificuldade de se entrar nesse "insólito livro de "memórias", conforme o designa em outro momento a autora (ARAÚJO, 2000, p. 18).

Não temos o propósito de realizar aqui uma discussão teórica a respeito do gênero autobiográfico, ou de examinar os tênues limites que o circunscrevem ou mesmo de discorrer sobre a imprecisão que marca o trabalho de qualquer memorialista — aliás imprecisão exposta com clareza por Pedro Nava em belo trecho de Balão Cativo:

Para quem escreve memórias, onde acaba a lembrança, onde começa a ficção? Talvez sejam inseparáveis. Os fatos da realidade são como pedra, tijolo — argamassados, virados parede, casa, pelo saibro, pela cal, pelo reboco da verossimilhança manipulados pela imaginação criadora (NAVA, 1986, p. 366).

O que nos interessa não é esse caráter ficcional "quase à revelia” (MOISÉS, 1997?, p. 164) do relato autobiográfico de Murilo (e, em suma, de qualquer relato autobiográfico), e sim a construção manifestamente literária de $A$ idade do serrote, que deixa o leitor perplexo, não sabendo exatamente onde está pisando, e que chamou tanto a atenção da fortuna crítica. Por exemplo, Carlos Drummond de Andrade (1968, p. 1), em crônica quando do lançamento do livro, observava admirado: "Saio da leitura com a sensação de que desembarco de uma cápsula espaço-temporal equipada com aparelhos mágicos. $\mathrm{E}$ esses aparelhos são apenas os recursos literários de Murilo”. E Paulo Rónai, também no calor da hora, já apreendia com agudeza o cerne da autobiografia:

Este livro de prosa, pois, envolve-nos numa corrente de poesia não menos forte do que os livros de versos mais veementes do poeta. Entretanto não obstante tantas afirmações de sua condição única de poeta, Murilo Mendes surpreende com sua vocação insuspeitada de ficcionista, se fazer ficção consiste em criar personagens. Cada um dos retratos a que aludimos levanta uma personagem de romance, mais de uma vez digna de ser protagonista, com seu halo, seu ambiente, seu drama ou sua comédia (RÓNAI, 1969, p. 6).

Mais recentemente, Augusto Massi (1995, vol. 3, p. 331) afirma de modo radical e surpreendente: "Murilo Mendes conseguiu escrever o único livro de memórias capaz de afirmar-se como obra de vanguarda”. Vê-se que as observações de Drummond, Rónai e Massi deixam à mostra a fatura sui generis de $A$ idade do serrote, relato autobiográfico que mescla poesia, ficção e experimentalismo.

Essa mesma questão é tratada por Antonio Candido em seu ensaio "Poesia e ficção na autobiografia”, no qual são examinadas, além das memórias de Murilo Mendes, também as de Carlos Drummond de Andrade - Boitempo e Menino antigo (Boitempo II) - e as de Pedro Nava — Baú de ossos e Balão cativo. Candido inicia seu texto, originalmente uma palestra, afirmando que os livros que vai comentar

podem ser qualificados de autobiografias poéticas e ficcionais, na medida em que, mesmo quando não acrescentam elementos imaginários à realidade, apresentam-na no todo ou em parte como se fosse produto da imaginação, graças a recursos 
expressivos próprios da ficção e da poesia, de maneira a efetuar uma alteração no seu objeto específico (CANDIDO, 1987, p. 51).

E mais adiante o crítico vai acrescentar que tal "cunho francamente poético e ficcional" vai possibilitar a leitura de tais autobiografias "reversivelmente como recordação ou como invenção, como documento da memória ou como obra criativa, numa espécie de dupla leitura, ou leitura 'de dupla entrada', cuja força, todavia, provém de ser ela simultânea, não alternativa” (CANDIDO, 1987, p. 54). Como é fácil notar, Antonio Candido e Laís Corrêa de Araújo têm abordagens bem distintas de $A$ idade do serrote: se Araújo titubeia entre uma leitura documental e uma ficcional, não sabendo muito bem como situar o objeto que tem nas mãos, Candido, ao contrário, propõe abertamente uma dupla leitura não excludente: não é uma ou outra, mas sim uma e outra ao mesmo tempo. A questão que se coloca é se há real possibilidade dessa leitura simultânea, pois, como declara o próprio crítico, $A$ idade do serrote é "autobiografia declarada, escrita em prosa" (CANDIDO, 1987, p. 54). Ou seja: tendo em vista a oposição, teorizada por Philippe Lejeune, entre pacto autobiográfico e pacto ficcional ${ }^{3}$, uma obra que se apresenta explicitamente como autobiográfica autorizaria uma leitura de "dupla entrada"? Essa questão será tratada um pouco mais adiante. Vale a pena no momento focalizar o ensaio de Candido com o propósito de investigar os elementos que, segundo o crítico, permitem que a autobiografia de Murilo seja qualificada de poética e ficcional, investigação que acabará mesmo por nos conduzir ao eixo central desta, já que o ensaio, apesar das poucas páginas que lhe são dedicadas, é fundamental para compreendêla.

A partir de uma leitura bastante esquemática do ensaio, pode-se dizer que o caráter ficcional e poético de $A$ idade do serrote deve-se a um duplo movimento transfigurador que abarcaria tanto o nível formal quanto o nível do conteúdo. O primeiro nível não se limitaria apenas ao trabalho mais artesanal e minucioso com a língua, que envolveria, por exemplo, o jogo estilístico com a sintaxe, com o ritmo, com a sonoridade, sendo o emprego experimental ou vanguardista da paronomásia um dos recursos mais recorrentes. Englobaria também a própria articulação estrutural do texto em seus diversos aspectos, dos quais Candido (1987, p. 57-58) lista alguns: a relativa autonomia dos tópicos (“os tópicos são

\footnotetext{
${ }^{3}$ O contrato ou pacto autobiográfico é o cerne do arcabouço teórico da obra de Philippe Lejeune sobre o gênero autobiográfico e é definido do seguinte modo no site proposto pelo autor: "é o compromisso que assume um autor de contar diretamente sua vida (ou uma parte ou um aspecto da sua vida) com um espírito de verdade" (LEJEUNE, 2006). Em outras palavras, o autor se compromete com o leitor em dizer a verdade sobre si mesmo ou pelo menos o que acredita ser verdadeiro. Nesse sentido o pacto autobiográfico se opõe ao pacto ficcional, já que neste não há tal compromisso, instaurando-se mesmo uma espécie de jogo em que o leitor finge acreditar no que é narrado. O texto autobiográfico, consequentemente, se apresenta como um ato real, que pode ser legitimamente verificado e que implica mesmo a responsabilidade social e jurídica de seu autor. Esse compromisso em dizer a verdade é reconhecido pelo leitor não somente por elementos internos ao texto, mas principalmente por aqueles que estão em seu limiar: às vezes pelo título (Memórias, Lembranças, Histórias da minha vida ...), às vezes pelo subtítulo ("autobiografia”, “diário"), às vezes por um prefácio, às vezes por uma nota do editor, etc. Mas o fundamental é que o pacto autobiográfico conduz à identidade de nome entre o nome do autor, que está grafado na capa, o do narrador e o do protagonista; e essa identidade se instaura como o elemento fundamental que define não só a autobiografia como todos os tipos de escrita do "eu". Em suma, o pacto autobiográfico é uma espécie de contrato de leitura proposto pelo autor ao leitor e que se fundamenta na identidade de nome entre autornarrador-personagem (LEJEUNE, 1996, 2002, 2006). As traduções dos textos de Lejeune são de minha responsabilidade.
} 
apresentados como unidades autônomas, ou semi-autônomas, à maneira de crônicas soltas"), a "técnica de tema-variação" (que corresponde a um duplo movimento de composição: de um lado, a fixação de um tema; de outro, seu desdobramento através de variações múltiplas), e a "modulação de estilo" ("a mudança sucessiva e organizada de tonalidade, maneira, composição"). Tais aspectos formais conduziriam a uma prosa que apresenta "um ímpeto de tal maneira transfigurador, que nós nos sentimos dentro da poesia, como primeiro fator que alarga o restrito elemento particular da recordação pessoal" (CANDIDO, 1987, p. 57).

Porém há também um processo de transfiguração, relativo ao nível temático ou do conteúdo, que visa à própria matéria vivida, já que

o Narrador não apenas transfigura o dado comum, ao mostrá-lo como algo tocado pelo cunho excepcional, mas introduz o insólito propriamente dito sob a forma de excentricidade, aberração da norma, loucura. Dá-se então um movimento pendular que unifica o texto em profundidade e estabelece a sua normalidade própria: o comum é visto como extraordinário; o extraordinário é visto como comum (CANDIDO, 1987, p. 59).

Institui-se assim "um mundo onde a loucura e o milagre são normais, do mesmo modo que o banal e o quotidiano são miraculosos" (CANDIDO, 1987, p. 58). Ou como afirma o próprio Murilo Mendes em trecho considerado decisivo por Antonio Candido: "movido por um instinto profundo, sempre procurei sacralizar o quotidiano, desbanalizar a vida real, criar ou recriar a dimensão do feérico" (MENDES, 1968, p. 62).

Talvez seja possível esquematizar do seguinte modo o processo constitutivo levado a cabo pelo escritor: há tanto um trabalho formal que direciona o relato testemunhal para o campo da ficção e da poesia como um trabalho de transformação que age sobre o próprio objeto do gênero autobiográfico ("a vida de um indivíduo escrita por ele mesmo", conforme a definição clássica dos dicionários ${ }^{4}$ ) com vistas a dar ao passado uma feição feérica ou sagrada. Advém, dessa forma, uma espécie de duplo processo de poetização, que obviamente não corre paralelo, mas que está absolutamente imbricado, sendo até mesmo difícil visualizá-lo separadamente: de um lado, o relato autobiográfico torna-se poético e ficcional; de outro, a matéria da memória se poetiza - poético aqui tomado num sentido bem amplo, significando a superação do prosaico em direção ao maravilhoso.

Exemplo desse duplo processo de poetização é o retrato de Desdêmona, "a viceputain juizforana", talvez o capítulo mais conciso e poético, ou mesmo de fatura mais experimental ${ }^{5}$. Dado o tamanho reduzido do texto, vale a pena citá-lo integralmente:

\footnotetext{
${ }^{4}$ Sigo aqui a definição do Aurélio (FERREIRA, A. B. de H.. Novo Dicionário da Língua Portuguesa. 2. ed. rev. e aum. 32. reimpr. Rio de Janeiro: Nova Fronteira, 1995).

${ }^{5}$ Quarenta e um capítulos compõem $A$ idade do serrote. É possível dividi-los em três grupos: o primeiro, que constitui a base de sustentação do relato autobiográfico, reúne 35 pequenos retratos de personagens que desempenharam uma função exemplar ou iniciatória na formação do protagonista-narrador (quase todos titulados com nomes próprios: "Etelvina", "Analu”, "Tio Chicó”, "Primo Alfredo”, "Hortênsia”, etc.); o segundo grupo abarca o primeiro (“Origem, Memória, Contato, Iniciação”) e o último (“O olho precoce”) capítulos — capítulos esses que apresentam uma função específica de abertura e de fechamento do conjunto, isto é, respectivamente de introdução e de conclusão; os quatro capítulos restantes ("Religião", "Momentos \& Frases”, "Confissões”, "A Rua Halfeld”) integram o último grupo e podem ser considerados como pequenas exceções no interior dessa estrutura,
} 


\section{DESDÊMONA}

Desdêmona miroares Desdêmona miroares Desdêmona desdenhosa com dois dês e os dedos manipulando homens, dados, cartas de baralho, miroares, penhoares atrevidos, vidros de cheiro homens homens homens; manipulando a mula-sem-cabeça o cigarro a torquês; Desdêmona desnuda desarrumada desnalgada desnatada; Desdêmona a viceputain juiz-forana (a titular era Ipólita); Desdêmona rebelde inconformista rompeu com a família, plantando as coxas na rua do amor industrializado excomungado; Desdêmona desdenhada que poluía noturnamente os meus lençóis, que animatografava os meus sonhos precoces; Desdêmona miroares Desdêmona mulher: despovoada desfeita revogada poderosa (MENDES, 1968, p. 82).

Não vamos aqui levar a termo uma análise detida do texto. Basta dizer que se está diante de uma prosa poética extremamente condensada, em que o aspecto sonoro se apresenta como o recurso axial da fatura. Composto apenas por um curto período, o leitor é sugado para o interior do texto por esse "contínuo ininterrupto" (CORMANICH, 1997, p. 146), cuja base é o jogo de repetições constituído por anáforas, aliterações, assonâncias, rimas internas e paronomásias. E no centro desse turbilhão sonoro encontra-se o nome da própria personagem, que não só é repetido nove vezes (ou mesmo dez, se considerarmos o título), como os próprios fonemas que o compõem são retomados e, consequentemente, disseminados pelos outros vocábulos ao longo desse breve capítulo. Poderosa Desdêmona que enrodilha os sentidos do próprio leitor.

Mas esse bloco sonoro acentuadamente lírico não deixa, no entanto, de cumprir seu papel na arquitetura do relato autobiográfico, visto que tanto delineia, mesmo que muito sinteticamente, o perfil da personagem - e mesmo traça com poucas pinceladas a história de sua vida — como indica a função que ela desempenha na formação do protagonista-narrador. Assim, o leitor se depara com a trajetória, do auge a decadência, da prostituta Desdêmona, figura sedutora que atiça o desabrochar dos sonhos eróticos do adolescente Murilo. Figura essa que, de humilde viceputain, é elevada à categoria de mulher fatal e demoníaca - movimento de ascensão em que o diálogo com a literatura e o mito (certamente ecos da diabólica Carmen, personagem da novela homônima do escritor francês Prosper Mérimée, e da figura mítica de Lilit, demônio feminino da tradição judaico-cristã, ressoam no interior do retrato) tem papel central ao arrancar a personagem de seu prosaísmo e alçá-la a outra dimensão, poética e maravilhosa.

Tendo diante dos olhos o extremado exemplo de "Desdêmona", como tratar então esse objeto insólito que embaralha testemunho, poesia e ficção? Se levarmos em conta, de modo "sectário e dogmático", a definição de autobiografia proposta por Philippe Lejeune em que a prosa é considerada elemento obrigatório - "narrativa retrospectiva em prosa que uma pessoa real faz de sua própria existência, quando focaliza especialmente sua vida individual, em particular a história de sua

\footnotetext{
visto que não têm por objeto o retrato de determinada personagem, mas giram em torno de temas específicos do tempo juiz-forano. "Desdêmona" é o vigésimo capítulo, encontrando-se, portanto, no centro do livro.

${ }^{6}$ Ao reavaliar algumas questões teóricas da sua obra, Lejeune afirma o seguinte a respeito da sua clássica definição de autobiografia: "Em meu espírito a definição era um ponto de partida para lançar uma desconstrução analítica dos fatores que entram na percepção do gênero. Mas, isolada de seu contexto, citada como uma 'autoridade', ela podia aparecer sectária e dogmática, [...] fórmula falsamente mágica que bloqueava a reflexão em lugar de estimulá-la" (LEJEUNE, 1983, p. 417).
} 
personalidade" (1996, p. 14, grifo nosso) — o estatuto autobiográfico de $A$ idade do serrote corre o risco de sofrer sérios abalos, pois o crítico ressaltou, inicialmente, que a poesia, ao colocar em evidência o próprio discurso, afetaria a verossimilhança da narrativa, solapando a confiança do leitor em um relato colado a um referente externo ${ }^{7}$. Talvez a leitura de Laís Corrêa de Araújo tenha escorregado exatamente nesse ponto ao se deixar contaminar com a prosa poética de Murilo Mendes que põe de cabeça para baixo, mesmo que não use a forma do verso, o que idealmente deveria ser a suposta transparência da linguagem do discurso autobiográfico.

O próprio Lejeune, no entanto, vai rever sua posição em relação à necessidade da prosa como um dos elementos caracterizadores do gênero; e, ao levar adiante suas reflexões sobre "o paradoxo da autobiografia literária", que "pretende ser ao mesmo tempo um discurso verídico e uma obra de arte" (1983, p. 423), afirma:

Assim, antes de propor uma definição que, secamente, exclui o verso, deveria ter designado como centro do sistema atual essa tensão entre a transparência referencial e a busca estética, e mostrar [...] que a partir de um ponto de equilíbrio existia uma gradação contínua de textos, indo, de um lado, em direção à insipidez do curriculum vitae, e, de outro, em direção à poesia pura. Nas duas extremidades do espectro, o contrato autobiográfico, por razões inversas, pode perder sua credibilidade. (LEJEUNE, 1983, p. 423-424).

Candido, ao propor uma dupla leitura que ocorreria simultaneamente, parece tangenciar de perto as colocações de Lejeune sobre o caráter paradoxal da autobiografia literária, pois vislumbra com clareza a tensão entre "transparência referencial" e "busca estética", ou seja, entre documento e invenção no interior do texto. Mas, para Candido, o caráter inventivo de $A$ idade o serrote parece não afetar a veracidade ou a credibilidade do relato, visto que em nenhum momento o coloca sob suspeita. Talvez a poetização do texto - essa gradação em direção à "poesia pura" - seja percebida pelo crítico não como algo que perturbe o pacto autobiográfico, mas sim como algo que tenha um determinado sentido na construção da história pessoal do poeta, ou melhor, na construção da versão de si mesmo que Murilo elabora em $A$ idade do serrote. Não por acaso, Candido afirma que o livro está "perfeitamente ambientado" na obra poética de Murilo, ou ao citar um "trecho decisivo", já referido anteriormente aqui, saliente que o mesmo "explica a atitude literária de Murilo Mendes em sua poeticidade total" (1987, p. 58), ou ainda finalize o ensaio retratando o poeta como um conciliador de contrários, retomando um lugar-comum da fortuna crítica. Em outras palavras: o crítico parece estar às voltas com certa articulação entre projeto autobiográfico e projeto poético.

Vale a pena então voltar mais uma vez à obra de Philippe Lejeune. Ao longo do livro L'autobiographie en France, o autor vai examinar várias questões teóricas referentes à autobiografia, o que o leva a uma constante retomada da definição do gênero, refinando-a com pequenas variações conforme o problema focado em cada momento. Em uma dessas passagens, Lejeune salienta o seguinte:

A autobiografia não pode, pois, ser simplesmente uma agradável narrativa de lembranças contadas com talento: ela deve, antes de tudo, tentar manifestar a

\footnotetext{
${ }^{7}$ Lejeune afirma que sua intenção, ao ressaltar a necessidade da prosa, era a de "afastar o que poderia paralisar a crença referencial, seja engendrando formas de suspeita, seja lançando o próprio leitor no imaginário” (1983, p. 423).
} 
unidade profunda de uma vida, deve manifestar um sentido, obedecendo às exigências muitas vezes contrárias da fidelidade e da coerência. Contar toda sua vida é impossível. A autobiografia repousa sobre séries de seleção: a seleção já feita pela memória, e a que faz o escritor sobre o que a memória lhe entrega. São retidos e organizados todos os elementos que têm uma relação com que o autor pensa ser a linha diretora de sua vida. As mais belas autobiografias são aquelas que conseguem conciliar essa pertinência - que tem a chance de ser fator de simplificação, de esquematização - com a riqueza e a variedade das experiências vividas (LEJEUNE, 1971, p. 21).

E ressalta, um pouco adiante, a necessidade de se "estabelecer um equilíbrio delicado, na organização da narrativa, entre a unidade de sentido e a presença afetiva do 'vivido' (ou da lembrança) e, no tom, entre a explicação e a evocação" (LEJEUNE, 1971, p. 21). Desse modo, o relato autobiográfico, segundo Lejeune, "parece, com efeito, ser um composto de romance e de ensaio: nos extremos do gênero se encontrariam, de um lado, a narração pitoresca e sugestiva [...]; de outro, a análise abstrata e sistemática" (1971, p. 22).

Talvez se possa, a partir dessas observações, vislumbrar duas faces que comporiam qualquer texto autobiográfico: de um lado, há um processo de construção de sentido que visa a conferir unidade e significado ao relato de vida, o que dá ao gênero um tom explicativo; de outro, a narrativa deve apresentar um caráter evocativo, pois o que está em jogo é o relato de uma série de acontecimentos revividos pelo autor, aparentando-se assim ao romance e, portanto, à ficção.

Em $A$ idade do serrote esse jogo entre as duas faces se apresenta, a meu ver, de maneira bastante equilibrada, o que dá a força e a qualidade do livro. Mas se a evocação do vivido se apresenta de maneira tão consistente, emaranhando o leitor na teia das lembranças encantadas e saborosas de Murilo, a busca da construção do sentido não é tão fácil de ser vislumbrada, visto que tanto o trabalho ousado com a forma (e aqui considero principalmente a fragmentação da narrativa e o trabalho poético com a linguagem) como a delimitação das memórias ao período da infância e da adolescência impõem, aparentemente, limites à manifestação de qualquer unidade ou significado que deveria amarrar o relato de vida. Mas se $A$ idade do serrote não é um mero espargimento de fragmentos soltos do passado, ela tem, com certeza, um sentido arquitetado com vistas à construção da imagem do narrador ${ }^{8}$. E é esse ponto que me parece essencial: como se dá essa construção? Ou melhor: em que se fundamenta a linha diretiva que dá sentido ao relato do processo de formação do autobiógrafo?

Lejeune observa que "a autobiografia é, para os escritores, uma escrita segunda: eles reinvestem então, em uma escrita referencial, as formas ou as teorias que eles primeiramente elaboraram sobre o modo da ficção ou da especulação" (2001, p. 51-52). Isso permite discernir a existência de uma espécie de articulação entre projeto autobiográfico e projeto poético: o escritor não só aplica na escrita autobiográfica os procedimentos formais que já vem experimentando na ficção ou na poesia, como o próprio projeto poético — e, em consequência, seus fundamentos ideológicos e estéticos - se caracteriza como o elemento basilar que dá ao relato de vida unidade e sentido. É preciso ressaltar, no entanto, que se o projeto poético sustenta o texto autobiográfico, este, por sua vez,

\footnotetext{
${ }^{8}$ Como diz Lejeune (1971, p. 84): “A autobiografia mostra, em toda a sua verdade, o trabalho que toda personalidade faz para se construir, a maneira pela qual todo ser vive sua história e a transforma em mito.”
} 
"pretende explicar retrospectivamente os textos do autor que de fato contribuíram a produzi-lo, e instaura assim um tipo de círculo" (LEJEUNE, 2001, p. 52). Configura-se então um vaivém entre autobiografia e projeto poético, um iluminando o outro, mas cujo ponto de partida é o próprio texto autobiográfico, pois se ele "diz a verdade é sobre o presente daquele que escreve (a imagem de sua vida que se deseja construir hoje) mais que sobre seu inacessível passado.” (LEJEUNE, 2001, p. 52). Concluise daí que o projeto poético é relido — e construído — pelo próprio autor a partir de um determinado momento de sua trajetória, momento esse que é o da elaboração da autobiografia.

A dupla poetização de $A$ idade do serrote parece então se afigurar como o eixo desse processo de articulação entre autobiografia e projeto poético, ou seja: a poetização do relato e da vida não deve ser vista como um elemento que estremece o pacto autobiográfico ou que encaminha a leitura para o campo ficcional, e sim como o ponto central que diz respeito à própria imagem do narrador que é construída no texto, imagem essa que se molda a partir dos fundamentos estéticos e ideológicos do projeto poético de Murilo. Mas se a poetização da experiência vivida — a transfiguração no nível temático — está intimamente ligada ao objeto do relato autobiográfico e é assim mais facilmente perceptível pelo leitor, não se deve, no entanto, deixar de lado a elaboração realizada no nível formal, pois, segundo Starobinski (1970, p. 257), “o estilo assume uma importância particular, já que à auto-referência explícita da própria narração, o estilo acrescenta o valor auto-referencial implícito num modo singular de elocução”. Em outras palavras: o trabalho com o estilo - ou com a forma em sentido mais amplo - também é uma marca fundamental do perfil do narrador, já que "está ligado ao presente do ato da escrita" (STAROBINSKI, 1970, p. 257) e diz respeito, portanto, à própria imagem deste que é esboçada no corpo do texto.

É possível agora retomar uma questão que ficou suspensa: a dupla leitura simultânea proposta por Candido é plausível? A observação do crítico de que $A$ idade do serrote é uma "autobiografia declarada" pode ser lida, de acordo com a base teórica de Lejeune, como a confirmação da identidade de nome entre autor, narrador e personagem e consequentemente como o estabelecimento do pacto autobiográfico. Isso quer dizer que ao longo do relato o leitor nunca coloca em dúvida a identidade do poeta Murilo Mendes, apesar de toda transfiguração operada na matéria da memória e de todo trabalho poético e ficcional no nível da forma. O pacto autobiográfico, portanto, se reafirma a cada instante, acarretando efeitos de leitura diversos dos do pacto ficcional.

Talvez a leitura como "invenção" ou como "obra criativa" possa então ser pensada em outra chave, qual seja: atrelada ao projeto autobiográfico do autor, abrindo assim a possibilidade de ser compreendida como o cerne desse mesmo projeto e não como uma opção de leitura independente, não obstante simultânea à leitura como "documento da memória". Dito de outro modo: a poetização das memórias da infância e da adolescência, que à primeira vista permite a abertura para uma leitura ficcional, parece se configurar como o elemento fundamental que sustenta o relato da formação do narrador e consequentemente a construção de sua imagem.

Este artigo, como o próprio título indica, apenas propõe o encaminhamento de certa leitura de $A$ idade do serrote, sem se preocupar, nesse espaço reduzido, em levar a cabo qualquer exame mais detido do texto. Buscou-se aqui, de certo modo, redirecionar, a partir de algumas considerações teóricas de Lejeune a respeito do gênero autobiográfico, a proposta de dupla leitura aventada por Candido, e com 
isso tornar mais palpável a importância, ou mesmo a necessidade, de uma articulação entre $A$ idade do serrote e os aspectos estéticos e ideológicos do projeto poético de Murilo Mendes. A poetização do relato, tanto no nível formal como no temático, certamente deve ser examinada a partir do cruzamento com as várias faces da poliédrica obra do poeta, essencialmente a católica, a surrealista e a experimental, sem deixar de lado o contexto histórico em que a autobiografia foi concebida, contexto que marcou tão fortemente a visão negativa e crítica que Murilo tem de seu tempo, patente, por exemplo, em sua obsessão pelo tema da bomba atômica. Eis aí, a meu ver, a base em que se deve apoiar a leitura, ou pelo menos uma das possíveis leituras, da saborosa, encantadora e insólita autobiografia de Murilo Mendes. 


\section{Referências bibliográficas}

ANDRADE, Carlos Drummond de. "Murilo Mendes, temponauta”. Correio da Manhã, Rio de Janeiro, 29 dez. 1968. Segundo Caderno, p. 1.

ARAÚJJ, Laís Corrêa de. Murilo Mendes: ensaio crítico, antologia, correspondência. São Paulo: Perspectiva, 2000.

CANDIDO, Antonio. "Poesia e ficção na autobiografia”. In: A educação pela noite e outros ensaios. São Paulo: Ática, 1987. p. 51-69.

CORMANICH, Rogério. Aspectos do feminino na re-invenção autobiográfica de Idade do Serrote de Murilo Mendes. 1997. 204 f. Dissertação (Mestrado em Teoria Literária e Literatura Comparada) Faculdade de Filosofia, Letras e Ciências Humanas, Universidade de São Paulo, São Paulo, 1997.

LEJEUNE, Philippe. "Qu'est-ce que le pacte autobiographique?" In: Autopacte: site proposé par Philippe Lejeune. 2006. Disponível em: <http://www.autopacte.org>. Acesso em: 30 dez. 2009.

Entrevista com Philippe Lejeune. Ipotesi: revista de estudos literários, Juiz de Fora: Editora UFJF, vol. 6, n. 2, p. 21-30, jul/dez 2002. Entrevista concedida a Jovita Maria Gerheim Noronha.

Autobiographie. In: Dictionnaire des genres et notions littéraires. 2. ed. Paris: Encyclopaedia Universalis, Albin Michel, 2001, p. 49-54. Le pacte autobiographique. 2. ed. Paris: Seuil, 1996.

Le pacte autobiographique (bis). Poétique: revue de théorie et d'analyse littéraires, Paris: Seuil, n. 56, p. 416-434, nov. 1983.

L'Autobiographie en France. Paris: Armand Colin, 1971.

MASSI, Augusto. "Murilo Mendes: a poética do poliedro". In: PIZARRO, Ana (org.). América Latina: palavra, literatura e cultura: vanguarda e modernidade. São Paulo: Fundação Memorial da América Latina; Campinas: UNICAMP, 1995, v. 3. p. 319-333.

MENDES, Murilo. A idade do serrote. Rio de Janeiro: Sabiá, 1968.

MOISÉS, Massaud. “Outras expressões híbridas”. In: A criação literária: prosa II. 15. ed. rev. e atual. São Paulo: Cultrix, 1997. p. 153-167.

NAVA, Pedro. Balão cativo. 4. ed. Rio de Janeiro: Nova Fronteira, 1986.

RÓNAI, Paulo. A nova face de Murilo Mendes. O Estado de São Paulo, 06 dez. 1969. Suplemento Literário, ano 14, n. 651 , p. 6.

STAROBINSKI, Jean. Le style de l'autobiographie. Poétique: revue de théorie et d'analyse littéraires, Paris: Seuil, n. 3, p. 257-265, 1970.

Referência eletrônica: LOUREIRO, Jayme. A idade do serrote: encaminhamento de uma leitura, Revista Criação \& Crítica, $\mathrm{n}$. 4, p. 26-35, 2010. Disponível em:

<http://www.fflch.usp.br/dlm/criacaoecritica/dmdocuments/03CC_N4_JLoureiro.pdf> 